\title{
Migration in and out of Southeastern Europe. Values, Networks, Wellbeing
}

In July 2015 the Institute for East and Southeast European Studies - the home of this journal-hosted its $3^{\text {rd }}$ Annual Conference. The title of the event was 'Migration in and out of East and Southeastern Europe. Values, Networks, Well-Being' and it brought together researchers from the social sciences and the humanities, who together clearly demonstrated how much value multi- and interdisciplinary approaches add to the study of migration. As befits this journal, the contributions to that conference inspired us to assemble migration research focused on Southeastern Europe which looks at present or, rather, recent developments. Three of the five papers in this special issue of Südosteuropa were presented and discussed during that July 2015 conference, while the other two papers, respectively by Nermin Oruč and Amina Tabaković and by Ana Aceska, were specially commissioned for this issue.

Whereas the bulk of the scientific literature on the topic concentrates on the effects of migration within the society immigrated to, both the conference and the papers in this volume look too at the situation in countries emigrated from; in a way the phenomenon of return migration combines both elements along the time axis.

\section{GUEST EDITORS}

Jürgen Jerger

holds the Chair of International and Monetary Economics at Regensburg University and is Director of the Institute for East and Southeast European Studies.

Michael Knogler

is Senior Researcher at the Institute for East and Southeast European Studies.

Return migration is the topic of the first paper, by Selma Porobić on 'Bosnian "Returnee Voices" Communicating Experiences of Successful Reintegration. The Social Capital and Sustainable Return Nexus in Bosnia and Herzegovina.' Porobić conducted illuminating interviews with returned migrants in three municipalities that experienced an enormous amount of war-displacement during the 1990s and substantial subsequent return migration. Clearly, ethnic conflicts in the region are still a major challenge requiring 'social bridging' efforts between groups as well as 'social bonding' within homogenous groups. A third dimension, 'social linking', looks at the relationship between individuals or groups and state institutions. Porobić critically assesses the roles both of external help by humanitarian organisations such as the UNHCR, and the local and regional organisation of people-what she calls 'grass-roots ac- 
tivism' - along these dimensions. From her fieldwork, Porobić has concluded that positive developments are more likely the less political interference there is, especially since politics and policymakers are still noticeably divisive along traditional lines whereas ordinary people are much more willing to engage actively in social bridging.

A very different effect of migration on the same region of emigration is analysed in the paper entitled 'Motives for Remittances Change During the Financial Crisis in Bosnia and Herzegovina', by Nermin Oruč and Amina Tabaković. Like many other emigration regions, Bosnia and Herzegovina relies to a significant degree on remittances, and it is indeed plausible to suggest that the economic and financial crisis has affected both receivers and the senders of them. Using household panel data from 2007 and 2011, Oruč and Tabaković aimed to identify changing motives for sending remittances, and data from 2011 reveal the increasing importance since the crisis of the altruistic motives of the senders of remittances, whereas the 2007 data show that exchange motives dominated. The empirical strategy used to show this consisted of allowing for a non-monotonic relationship between remittances and the income of a receiving household, taking into account social benefits. The result implies that to some extent both remittances and social benefits are substitutes for each other rather than complements. In other words, for the receiver more generous social benefits will lead to lower remittances.

Remittances play a major role in the Ukraine too, the country examined in Iuliia Kuntsevych's paper 'Remittances, Spending and Political Instability in Ukraine'. Kuntsevych has used data from the 2007 Ukraine Longitudinal Monitoring Survey to look at both the determinants of the probability of receiving remittances and the influence of remittances on the spending structure of households. The first question she asked of the data was whether an individual's political orientation (in terms of supporting the 2004 Orange Revolution) affected that person's likelihood of receiving remittances, and perhaps surprisingly, the data revealed that support for Yushchenko (rather than Yanukovych) did increase the chances of receiving remittances. Although the channel through which that effect may be explained is beyond the scope of this paper and that dataset, Kuntsevych offers the hypothesis that it might be linked to greater support for Yushchenko among emigrants. The effects of remittances in the receiving country depend mainly on the way they are spent; basically whether they 'only' shore up present consumption or are used for investment purposes as well. Kuntsevych shows that among other things remittances have a positive effect not only on human capital formation but also on individual ability and willingness to help others by making donations to them.

The remaining two papers look at the experiences of migrants in their respective immigration countries. In their study on 'East European Migrant Women 
in Greece. Intergenerational Cultural Knowledge Transfer and Adaption in the Context of Crisis', Domna Michail and Anastasia Christou report on some of the very personal migration stories of women who left East European countries to go to Greece. The authors talked to Albanian, Bulgarian, Romanian and Polish women now living in Greece, and if the insights they gained do not lend themselves to easy generalisation, nevertheless specific cultural motives and behavioural patterns derived from the women's home countries emerge very clearly. Albanian women, for example, are seen emphasizing the aspect of personal freedom and economic opportunities as major reasons to emigrate, and that reflects the more paternalistic society in Albania. By asking the women about how their children are dealing with the challenges and opportunities of their dual backgrounds, Michail and Christou show how such families live 'transnational lives' responsive to their respective situations, for example in relation to the economic and financial crises. A rather positive aspect is that many mothers were actively and consciously preparing their children for a transnational mobility they hope will enhance their chances in life.

This last aspect of potentially benefiting from one's home background in a future professional life in the country of immigration is what takes centre stage in Ana Aceska's paper on 'Transnational Experts, Rooted Careers. Migrant Professionals from Macedonia in Germany'. Aceska explores the insights she has gleaned from interviews with twelve highly qualified migrant professionals. Of course, these are success stories, but she finds that these professionals perceive their status as transnationals as a source of social, economic, and cultural capital. They feel they have been able to achieve unique positions in their work because they could draw on their transnational ties, networks and experiences. At the same time, all of them have rooted their careers in the same place, Germany - in fact in the same institution. As a result, these migrants have been aiming more or less at the same linear and stable career as their German colleagues, so naturally they take those colleagues as a point of reference for their development. Although the positive perception of the respective provenance might be wishful thinking for many migrant workers, the examples given in Aceska's paper are certainly encouraging. And it might be remarked that empirical economic research has quite firmly established the added value of cultural and ethnic diversity to the productivity of workers - and that is perfectly in line with Aceska's findings.

Overall, the papers in this issue show once again that migration is an extremely multi-faceted phenomenon having important effects on economies and societies in both immigration and emigration countries - indeed in basically any area one might think of. They very clearly convey the complexity of the determinants and consequences of migration and their changes across time and space; and on 
a theoretical note point up the intellectual benefits of different methodological approaches, ranging from sophisticated statistical and econometric analyses of huge datasets to wide-ranging interviews even with a necessarily limited numbers of individual migrants. 